\title{
Reducing gun violence in America
}

Jens Ludwig ${ }^{a, b, 1}$

The rate of gun violence in the United States substantially exceeds that of most other developed nations (1). Within the United States, gun deathsparticularly homicides-contribute to disparities in life expectancy between whites and minority groups, particularly African-Americans (2). Scientific progress in understanding how to address this problem has been limited in part because of limited research funding, which itself is largely due to the politics around guns in America (3). Therefore, the new article in PNAS by Luca et al. (4) addresses a critical topic.

In their new paper, Luca et al. argue that the adoption of mandatory waiting periods for handgun purchases reduces gun homicides by about $17 \%$. These estimated effects are enormous. Most remarkable of all is that the policy intervention that leads to these reductions in gun violence would seem to impose so few costs on society. In what follows, I first try to put the magnitude of Luca et al.'s estimates into context to help readers appreciate how large they actually are. Moreover, if the results are correct, they would imply that that almost all gun violence in America is committed by people with only transitory motivation. However, it is also possible that their estimates overstate somewhat the effects of waiting periods on gun violence. This is not intended as a criticism; the question they address is intrinsically difficult. Refining our understanding of this question is likely to require better data systems in the future.

Their analysis also raises a natural follow-up question: If these laws are so helpful, why do only 16 states have such policies currently in place? The answer seems due in part to what has been called the "collective action problem" (5) that leads a small but highly motivated minority of the population to dominate the legislative process. This theory predicts that alternative paths to policy change, such as ballot referenda, should be more likely to result in additional firearm regulations like waiting period requirements. This prediction seems consistent with the experience of several states in recent years.

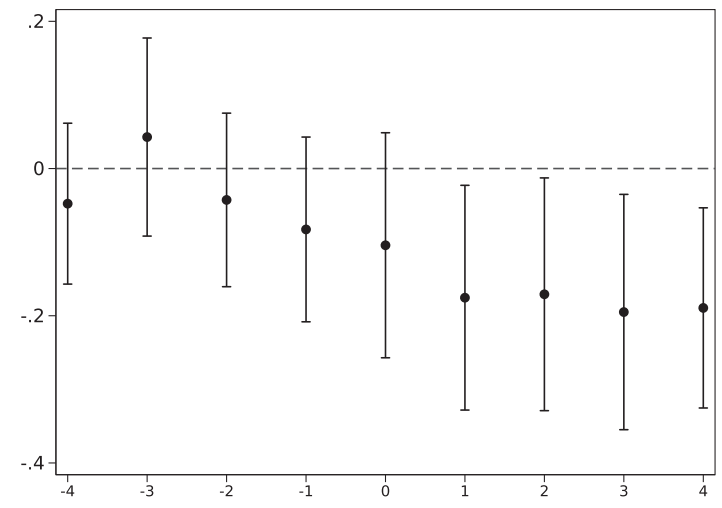

Fig. 1. Differences in log gun homicide rates between states that did versus did not change waiting periods due to the Brady Act, by year before or after Brady. Source: Figure generously provided by Luca et al. and from reestimating their main equation with log gun homicide rate as the dependent variable, but replacing the binary indicator for whether a waiting period is in effect with a series of indicator variables for whether the state-year observation is $X$ years before or after adoption of a waiting period ( $X$ from -4 to +4 , shown along the $x$ axis). The figure plots the estimates and $95 \%$ confidence intervals for the coefficients on these indicator variables, so the $y$ axis is percentage change divided by 100 .

The Effects of Waiting Periods on Gun Violence The system of gun regulation in the United States sets a relatively modest floor of federally required regulations that cities and states can then supplement on their own if they so choose. The federal Gun Control Act (GCA) of 1968 prohibited firearm acquisitions by minors, adults with felony convictions, illegal aliens, and those confined by court order due to mental illness. However, the GCA did not actually require federally licensed firearm dealers (FFLs) to do much to determine the purchaser's eligibility.

Luca et al. examine the consequences of the "natural experiment" that arises from many states choosing on their own to require FFLs to carry out background checks of potential handgun purchasers,

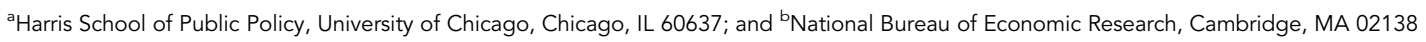
Author contributions: J.L. wrote the paper.

The author declares no conflict of interest. Published under the PNAS license.

See companion article on page 12162.

${ }^{1}$ Email: jludwig@uchicago.edu. 
as well as mandatory waiting periods. The challenge to social scientific studies of the effects of such state-initiated policies is the concern that the adoption of new gun laws may be consequence, not just cause, of local-area trends in gun violence, so that unmeasured factors that affect crime trends could lead to biased estimates for the effects of these laws.

For that reason, Luca et al. also capitalize on a second natural experiment: In 1994, the federal Brady Handgun Violence Prevention Act required background checks and (usually) 5 -d waiting periods for handgun sales in those states that had not already adopted these requirements on their own. That these changes in state laws are externally imposed, not initiated by the states themselves, may in principle help overcome concerns about confounding from omitted variables.

Luca et al. find waiting periods reduce gun homicides by about $17 \%$, with similar results if they focus just on the changes in state requirements created by the federal Brady Act. They find less consistent evidence that gun homicides are affected by background checks, and so their findings are in that sense consistent with those reported in ref. 6 . While in ref. 6 we followed the federal government's classification of which states were required to follow the Brady Act's requirements, which classified as "Brady states" those that changed either background check requirements or waiting periods, Luca et al.'s innovation is to exploit additional variation in changes in waiting periods and background checks separately within the set of states that were affected and exempt from Brady's requirements.

How large is a $17 \%$ reduction? As a way to put this estimate into context, from their recent peak in 1993 through 2001, gun homicide rates declined by $48 \%$ in the United States. Leading explanations for the crime drop include the tens of billions of dollars of additional government spending on prisons and police each year, plus major changes in social conditions such as the waning of the crack cocaine epidemic and abortion legalization (7). Luca et al.'s estimates, if taken at face value, suggest that a single policy change that imposes at most minor costs on society has an effect equal in size to about one-third of America's historic drop in gun violence in the 1990s.

Luca et al.'s estimates, if correct, would also potentially transform our understanding of the nature of gun violence. This can be seen by decomposing the effect of waiting periods on gun homicides into the product of four parameters: $\alpha$ is the share of offenders who are in what Luca et al. call a "visceral state" and have homicidal motivations that are transitory, rather than sustained; $\beta$ is the share of offenders in a visceral state who obtained a gun from a source that would impose a waiting period if it were required (an FFL in most states, but in some states this may also now apply to private sales as well); $\gamma$, the share of gun homicides by an offender in a visceral state where the gun was acquired from a source that would enact a waiting period, were there such a law in place, and was acquired within just a few days of the killing absent a waiting period; and $\delta$ is the effect of the waiting period on those events that logically could be affected by the law.

The best available research does not enable us to precisely estimate these parameters, but we can generate some defensible guesses for several of them. The share of those who commit murder with guns that obtained their gun from a source that would require a waiting period if such a law was in effect seems unlikely to be more than, say, $\beta \sim 40 \%$ (8). Surveys of offenders with guns in facilities run by the Illinois Department of Corrections suggest that something like $20 \%$ obtained their gun within $5 \mathrm{~d}$ of their crime (9). Even if my best guesses for $\beta \sim$
0.4 and $\gamma \sim 0.2$ are off by a fair margin, the only way that $\alpha \times \beta \times \gamma \times$ $\delta=0.14$, as Luca et al.'s estimates claim, would be if waiting periods worked perfectly in almost all of the cases for which they could work $(\delta \sim-1)$, and that almost all gun homicides in America are committed by people with transitory motivation $(\alpha \sim 1)$.

An alternative hypothesis is that Luca et al.'s estimates somewhat overstate the size of the impact on gun homicides due to waiting periods. Some support for this hypothesis comes from Fig. 1, generously created for me by Luca et al., which plots the difference in log of gun homicide rates between states that did and did not change their waiting period requirements as a result of the Brady Act for each year before and after Brady went into effect, controlling for all of the other explanatory variables used in Luca et al.'s main analysis. (Results for the full sample period are similar.) While the confidence intervals are somewhat large, the graph provides at least suggestive evidence that states that enact waiting periods experienced a decline in gun homicides starting about 3 y before the laws go into effect. This would be consistent

\section{In their new paper, Luca et al. argue that the adoption of mandatory waiting periods for handgun purchases reduces gun homicides by about $17 \%$.}

with confounding from unmeasured variables in Luca et al.'s analysis, although it does also seem possible the preexisting downward trend may have accelerated when waiting periods go into effect.

Better data systems would enable the scientific community to refine Luca et al.'s estimates by, for example, focusing just on those violent events where we think waiting period policies could have some impact, or constructing more comparable intervention and control groups to compare. Investments in better data would not only strengthen the field's ability to understand the effects of waiting periods but also facilitate research more generally on how to control gun violence.

\section{Gun Policy Politics}

Luca et al.'s new study suggests that waiting periods may save lives, although the exact size of the reduction remains to be determined by future research. Large majorities of the American public, from 65 to $86 \%$, support waiting period requirements; even majorities of gun owners support these policies (see, for example, the survey results summarized at lawcenter.giffords.org/ polling-on-waiting-periods/). So why do only 16 states currently have such laws in effect?

Public discussions point to the power of single-issue advocacy organizations like the National Rifle Association (NRA). The common conclusion is to believe that the power of the NRA means gun politics are in a permanent state of paralysis.

However, social science research has more to say on this point. The "collective action problem" (5) would seem to apply here as well: firearm regulations that enhance public safety are a "public good" that everyone would benefit from, but each individual's motivation to incur the costs to achieve it (such as lobbying on behalf of new laws, or letting this single issue outweigh others in one's choice of politician to vote for) are limited. This leads to a situation in which a small but motivated subset of the population (such as gun owners who 
believe any regulation is a violation of the Second Amendment, or the start down some slippery slope toward repeal of gun rights) can dominate the legislative process.

There is a testable prediction of this theory: mechanisms that reduce the costs of achieving policy change for the majority of weakly motivated people who support additional gun regulations will have a greater chance of success than the usual legislative process. One example of such a mechanism is the ballot referendum. Consistent with these predictions, Oregon's Measure 5 (expanding the set of gun transfers for which background checks are required to include, for example, gun shows) received $61.8 \%$ of the public's vote-much higher than the $47.0 \%$ of the state's vote received by the Democratic candidate for president that year (Al Gore). A similar referendum in Colorado in 2000 (Initiative 22) received $70 \%$ of the vote, compared with the $42.4 \%$ vote share for Al Gore.

What remains to be seen is whether the insights from this social science theory wind up changing the political strategies of gun control proponents over time. If waiting periods are even a fraction as effective as Luca et al.'s estimates suggest, the result could be sizable reductions in this most uniquely American public policy (and public health) challenge.

1 Richardson EG, Hemenway D (2011) Homicide, suicide, and unintentional firearm fatality: Comparing the United States with other high-income countries, 2003. J Trauma 70:238-243.

2 National Center for Health Statistics (2016) Health, United States, 2015: With Special Feature on Racial and Ethnic Disparities (National Center for Health Statistics, Hyattsville, MD).

3 Braga AA, et al. (2013) Open letter to the Biden Commission. Available at urbanlabs.uchicago.edu/attachments/store/87d0b65482039c9b4c44fa426e57bcc49ecd 1929c1c1e0edc65218cc4eb7/Biden+Commission+letter_20130110 final.pdf. Accessed October 23, 2017.

4 Luca M, Malhotra D, Poliquin C (2017) Handgun waiting periods reduce gun deaths. Proc Natl Acad Sci USA 114:12162-12165.

5 Olsen M (1965) The Logic of Collective Action: Public Goods and the Theory of Groups (Harvard Univ Press, Cambridge, MA).

6 Ludwig J, Cook PJ (2000) Homicide and suicide rates associated with implementation of the Brady Handgun Violence Prevention Act. JAMA 284:585-591.

7 Levitt SD (2004) Understanding why crime fell in the 1990s: Four factors that explain the decline and six that do not. J Econ Perspect 18:163-190.

8 Miller M, Hepburn L, Azrael D (2017) Firearm acquisition without background checks: Results of a national survey. Ann Intern Med 166:233-239.

9 Cook PJ, Parker ST, Pollack HA (2015) Sources of guns to dangerous people: What we learn by asking them. Prev Med 79:28-36. 